\title{
Letters
}

Website: bmj.com

Email: letters@bmj.com

\section{Alteplase for stroke}

\section{Uncertainty remains about efficacy}

EDITOR-The article by Lenzer and the associated commentary by Saver et al raise many serious issues, among which is the residual state of uncertainty concerning the efficacy of alteplase (tPA) in acute ischaemic stroke. ${ }^{1}$ Confronted by opposing interpretations of the aggregate data published to date and the now known baseline imbalance in the severity of stroke in the National Institute of Neurological Diseases and Stroke (NINDS) trial, doctors are presented with a conundrum: what action do the data support?

The reported unwillingness of the investigators and sponsor of the National Institute of Neurological Diseases and Stroke trial to provide data for additional analysis is disturbing. Emanuel et al have described seven requirements for the ethical conduct of clinical research, among which is social and scientific value. ${ }^{2}$ Social value presupposes the public dissemination of research results. I have formulated a standard for the scientific and ethical review of trials that elaborates on this requirement. ${ }^{3}$

Implicit in this requirement is the necessity for the public dissemination of the complete dataset acquired during a clinical trial.

\section{Advice to authors}

We prefer to receive all responses electronically, sent directly to our website. Processing your letter will be delayed unless it arrives in an electronic form.

We are now posting all direct submissions to our website within 24 hours of receipt and our intention is to post all other electronic submissions there as well. All responses will be eligible for publication in the paper journal.

Responses should be under 400 words and relate to articles published in the preceding month. They should include $\leqslant 5$ references, in the Vancouver style, including one to the BMJ article to which they relate. We welcome illustrations.

Please supply each author's current appointment and full address, and a phone or fax number or email address for the corresponding author. We ask authors to declare any competing interest. Please send a stamped addressed envelope if you would like to know whether your letter has been accepted or rejected.

Letters will be edited and may be shortened.

bmj.com

letters@bmj.com
This allows interested investigators to apply recognised analytic techniques in an attempt to resolve (or diminish) residual uncertainty concerning the clinical implications of the trial's results. This ethical requirement has not yet been met for the National Institute of Neurological Diseases and Stroke trial.

Howard Mann program associate

Division of Medical Ethics, University of Utah School of Medicine, Salt Lake City, UT 84132, USA howardm@xmission.com

Competing interests: None declared.

1 Lenzer L. Alteplase for stroke: money and optimistic claims buttress the "brain attack" campaign [commentarie by C Warlow; JL Saver, CS Kidwell, S Starkman]. BM 2002;324:723-9. (23 March.)

2 Emanuel E, Wendler D, Grady C. What makes clinical research ethical? JAMA 2000;283:2701-11.

3 ASSERT. A standard for the scientific and ethical review of trials. wwwassert-statementorg/publication $\mathrm{html}$ resultsdissem

\section{Patients and doctors are being misled by} promotional pressures

EDITOR-Alteplase (tPA) is not proved for the treatment of stroke, and payment from the drug's manufacturers to research doctors degrades the premise of unbiased skill.

In their commentary Saver et al disclose ties to 81 for profit companies linked to treatments for stroke. ${ }^{1}$ Sponsorship of this magnitude does not "channel the self interest of profit making companies to improving stroke care": it purchases spokesmen for manufacturers seeking to add credibility to their wares. Although sponsored doctors can perform impartial research, it is impossible to determine whether their research is truly unbiased and is much simpler to believe consultants without such ties.

We are troubled by the claim that alteplase has been proved in pooled data from six trials. Of these, only the Nationa Institute of Neurological Diseases and Stroke (NINDS) trial rigorously measured the efficacy of alteplase within a predetermined three hours of stroke onset. The remainder of the trials were post hoc analyses that routinely ignored negative results and showed increased mortality in the alteplase treatment groups. Such data manipulation is contrary to meta-analysis methodology and confounds the truth. ${ }^{2}$

It is important to compare the benefit and harm in the National Institute of Neurological Diseases and Stroke trial. For every nine patients treated, one benefited. For every 16 treated, one was harmed by cranial haemorrhage. For every 34 treated, one died as a result of such haemorrhage. Thus for every four patients who benefited, one died. These numbers do not support the statement that treatment with alteplase is highly efficacious.

Given the animosity of this debate, we wonder if the future of medicine will rely on investigators with such ties to for profit companies and if the results of the National Institute of Neurological Diseases and Stroke trial will ever be confirmed by independent reanalysis or randomised trial. (Its data remain unavailable despite claims that its results are so compelling that further randomised controlled trials are unethical.)

Until this trial's conclusions are verified, and given the drug's potential for catastrophic harm, we strongly disagree with the premise that the public should be targeted in campaigns to increase the number of stroke patients treated with alteplase. In a treatment window of only three hours, doctors unfamiliar with the specific risks of alteplase cannot properly do all the assessments needed. Patients and doctors are being misled by promotional pressures to give the drug as widely as possible.

James $\mathbf{L i}$ assistant professor of medicine Larry A Nathanson instructor of medicine Division of Emergency Medicine, Harvard Medical School, Cambridge, MA 02115, USA jamesli@harvard.edu

Trevor J Mills assistant professor

Division of Emergency Medicine, Southwestern

Medical Center, University of Texas, Dallas,

TX 75390, USA

Karin E Netland clinical faculty, emergency medicine Charity Hospital, Louisiana State University School of Medicine, New Orleans, LA 70112, USA

Richard Paula clinical faculty, emergency medicine Tampa General Hospital, University of South Florida, Tampa, FL 33606, USA

Douglas Ragland clinical faculty, emergency medicine John C Lincoln Hospital, Arizona School of Health Sciences, Phoenix, AZ 85020, USA

Competing interests: None declared.

1 Lenzer L. Alteplase for stroke: money and optimistic claims buttress the "brain attack" campaign [commentaries by C Warlow; JL Saver, CS Kidwell, S Starkman]. BMJ 2002;324:723-9. (23 March.)

2 Moher D, Cook DJ, Eastwood S, Olkin I, Rennie D, Stroup Moher D, Cook DJ, Eastwood S, Olkin I, Rennie D, Stroup D. Improving the quality of reports of meta-analyses of Lancet 1999:354:1896-900.

\section{American Heart Association explains} how guidelines were formulated

EDitor-On behalf of the American Heart Association I wish to set the record straight on claims that "money and optimistic claims buttress the 'brain attack' campaign" for using alteplase (tPA) in stroke.

In accord with its established policies, the American Heart Association implemented a 
thorough, multilevelled process to prevent any individual or special interest from unduly influencing its guidelines 2000 for cardiopulmonary resuscitation and emergency cardiovascular care. ${ }^{2}$ In addition, a formal evidence based system was used to evaluate scientific data, formulate recommendations, and classify final recommendations.

The development of the guidelines took more than 18 months and involved more than 300 of the world's leading resuscitation experts. The final published recommendations resulted from countless hours spent by panel committees, international scientific councils, an international editorial board, members of the Emergency Cardiovascular Care Committee of the American Heart Association, and writing groups.

All those who developed the guidelines adhered to the American Heart Association's stringent conflict of interest policies and procedures. Participants submitted disclosure forms reporting all relevant relationships with external organisations, groups, and companies. The chairs of panels and subcommittees reminded participants to report these relationships and, if necessary, asked them to refrain from discussion or voting. The relationships reported by panelists are published in the proceedings of the guidelines 2000 conference in the Annals of Emergency Medicine. ${ }^{3}$

In its more than 75 years the American Heart Association has earned its reputation as a trusted authority by remaining an independent, objective leader focused on reducing disability and death from cardiovascular disease.

David Faxon president, American Heart Association Cardiology Section, University of Chicago, Chicago, USA

tagni.osentowski@heart.org

Competing interests: None declared.

1 Lenzer L. Alteplase for stroke: money and optimistic claims buttress the "brain attack" campaign [commentarie by C Warlow; JL Saver, CS Kidwell, S Starkman]. BM 2002;324:723-9. (23 March.)

2 Guidelines 2000 for cardiopulmonary resuscitation and emergency cardiovascular care. Circulation 2000;102 (8 suppl). [Whole supplement.]

3 Proceedings of the guidelines 2000 conference for cardiopulmonary resuscitation and emergency cardiovascular care: an international consensus on science. Ann Emerg Med 2001;37(4 suppl):S1-200.

\section{Financial information is needed to ensure objectivity}

EDITOR-Saver et al dismiss Lenzer's recommendation of avoidance of all potential bias as "unworkable and undesirable" and "extreme financial correctness" that would leave development of clinical guidelines to "ill equipped" non-experts. ${ }^{1}$

Her recommendation is neither unworkable nor undesirable. Financial correctness is exactly what is needed to ensure objectivity. One need not have participated in research to be an expert; one need only have a thorough understanding of the subject and a comprehensive knowledge of the literature. If participation in related research might be valuable, the financial conflicts that arise from it could be mitigated by more research being funded with public money: that is a direction in which we should be moving.

Saver et al claim that thrombolytic agents are highly efficacious in stroke. This assertion is not supported by a single published study. The only positive randomised trial had a number needed to treat of nine and a number needed to harm of 17 this hardly supports the description "highly efficacious." All other numbers that seem positive are the product of statistical manipulation and data snooping. Efforts to identify possible benefit by post hoc analysis of unplanned subgroups are useful only to generate hypotheses to test in further prospective trials.

According to Saver et al, "Concerns about the everyday effectiveness ... constitute a call to action, not resignation.” The call to action of the Cleveland area experience is the re-examination of available data and recommendations and an attempt to replicate the results of the only randomised controlled trial (the National Institute of Neurological Diseases and Stroke (NINDS) trial) that seemed to show benefit. The abysmal results obtained when reporting is nonselective reinforce doubts as to whether they might be replicated in another formal randomised controlled trial.

The authors declare that "Physicians caring for acute stroke patients can and should master the key elements of thrombolytic care or allow patients to be diverted to specialised ... centres where thrombolytic therapy can be expertly administered." Physicians should master the key elements of care that are of proved benefit. Fibrinolytic treatment is not yet one of those elements. Patients with potentially unstable disease should not be diverted in order to receive a treatment with a possibly unfavourable risk:benefit ratio, especially as most of them will be found not to be candidates for that treatment.

It may be true, as Saver et al claim, that treatment within 90 or 120 minutes would do more good than harm, but such a hypothesis has not been prospectively validated. Until that time, it seems appropriate to remember "First, do no harm."

Robert C Solomon professor of medicine Ohio Valley Medical Center, Wheeling, WV 26002, USA

rcsmdnet@nauticom.net

Competing interests: None declared.

1 Lenzer L. Alteplase for stroke: money and optimistic claims buttress the "brain attack" campaign [commentaries by C Warlow; JL Saver, CS Kidwell, S Starkman]. BM 2002:324:723-9. (23 March)

\section{Why were these authors of the} commentaries chosen?

EDITOR-Lenzer's article on conflicts of interest surrounding recommendations for the use of alteplase (tPA) in ischaemic stroke is important. ${ }^{1}$ Despite Saver et al's startling suggestion in their commentary that it would be undesirable for influential organisations to rely on experts without any financial conflict of interest, most readers will be disturbed by the facts that Lenzer gives. We can decide for ourselves whether the changes she suggests are cogent.

I am less sanguine, however, about the choice of authors of the accompanying commentaries. All four authors have financial relations with makers of alteplase. Couldn't the $B M J$ have found even one author without such a tie? Is it tacitly supporting Saver et al's extraordinary claim that it is impossible to be an expert on a subject about which one does not have a conflict of interest-even when the subject is conflict of interest itself?

Equally distressing is the $B M F$ s decision to publish an unopposed dismissal of criticism of alteplase for stroke. Lenzer is not a scientist, so it was appropriate that she merely referenced concerns of critics without trying to argue their points in detail. Would the $B M J$ have solicited two contrary commentaries had her article praised the use of alteplase? (The BMJ could hardly have predicted Warlow's cautionary stance, since he is an investigator in the third international stroke trial (IST-3), "designed to generate the data needed to persuade everyone involved in stroke medicine ... that rt-PA [recombinant tPA] thrombolysis should be more widely available.")

It is ironic that Saver et al's commentary was published immediately before an article from the series on evidence based medicine, as it is replete with distorted and selective reasoning that violates fundamental principles of clinical epidemiology. Allowing these authors to dismiss Lenzer's concerns-with the implication that they are experts, while she is merely an intemperate journalistwithout dissent from opposing experts encourages readers to pay less attention not only to the debate about stroke but also to the influence of money on policy recommendations. "So what if there are competing interests," one might conclude, "if the evidence is so clearly favourable," as Saver et al proclaim.

If the $B M J$ felt compelled to solicit this attack on critics of alteplase why did it not also solicit a balancing article so that readers could understand the debate and reach their own conclusions? Any number of us who believe that the evidence is far from conclusive, and who worry that widespread community use of alteplase for stroke might do more harm than good, would surely have been willing to write that article.

Jerome R Hoffman professor of medicine University of California at Los Angeles School of Medicine, Los Angeles, CA 90077, USA jrh@ucla.edu

Competing interests: JRH has provided expert consultation in lawsuits against physicians involving the issue of use of alteplase (tPA) in acute stroke. He has taken no personal compensation for this work, having donated all fees to the UCLA (University of California at Los Angeles) emergency medicine residency programme.

1 Lenzer L. Alteplase for stroke: money and optimistic claims buttress the "brain attack" campaign [commentaries by C Warlow; JL Saver, CS Kidwell, S Starkman]. BMJ 2002;324:723-9. (23 March.) 


\section{Author's reply}

EDITOR-As noted by Mann and Li et al, ethical questions arise when the full datasets of research trials are not made public and when the guidelines issued in response to those trials are made by those with competing financial interests.

Faxon writes: "All those who developed the guidelines ... submitted disclosure forms reporting all relevant relationships with external organisations, groups, and companies." He omits to mention, however, that the American Heart Association kept the "disclosures" of its stroke panellists secret, refusing to allow the public to know what was "disclosed." Moreover, public disclosures came only after I started an investigation into why the association did not mention financial conflicts with its original guidelines. This is a good first step. However, it would be far better if the association enacted a policy change that would require routine public disclosure of all competing interests for all of its guideline authors.

The claim by Saver et al in their commentary to my article that experts cannot be found without financial conflicts coincides with the recent and profoundly disturbing assertion by the editor of the New England Journal of Medicine that it cannot find experts without financial conflicts (a point contested by a former editor of JAMA (ABC News, 12 June 2002), ${ }^{1}$ prompting it to accept review articles by experts who will be limited to \$10000 annually from each pharmaceutical company. Saver et al list ties to 81 corporations; if an expert consults for five to 10 companies $\$ 50000-100000$ is added annually to his or her income.

One need only recall the thyroid storm debacle to realise the risks of mixing promotional interests with scientific inquiry. ${ }^{2}$ The manufacturer of Synthroid wanted to prove that it was superior to far cheaper generic preparations, so Flint Labs (later acquired by Knoll) hired Dr Betty Dong to prove their case. When her research failed to yield the desired results, Knoll launched a seven year campaign of harassment against Dr Dong when it learnt that she planned to publish her data despite its negative implications for sales. Knoll successfully blocked publication of her results until 1997, when they were published in $J A M A$, along with a damning editorial about bias and delay. ${ }^{3}$ Clearly, private financial interests did not serve the public health interests-or that of the public budget.

These events should serve as a warning shot: the line between science and marketing is being rapidly erased. Experts without competing interests may be hard (though not impossible) to find, but it begs the question: what is to be done? So long as public funding is curtailed, many scientists and not for profit organisations will be driven into the arms of corporations. Unless we are willing to support a degree of public funding necessary to attain truly disinterested and objective science, potentially critical conflicts of interest of this sort are inevitable.
Jeanne Lenzer medical investigative journalist Oak Ridge Journalism, Ellenville, NY 12428, USA Jlenzer1@csi.com

Competing interests: None declared. 1 Drazen JM, Curfman GD. Financial associations of authors.
NEngl J Med 2002;346:1901-2.
2 Rennie D. Thyroid storm. JAMA 1997;277:1238-43.
3 Dong BJ, Hauck WW, Gambertoglio JG, Gee L, White JR,
Bubp JL, et al. Bioequivalence of generic and brand-name
levothyroxine products in the treatment of hypothyroid-
ism. JAMA 1997;277:1205-13.

\section{Authors of commentary reply}

EDITOR-The statements of Solomon and Li et al about the number needed to harm with alteplase (tPA) are misleading. tPA causes more patients to bleed - the number needed to treat to cause symptomatic intracerebral haemorrhage does approximate 17. However, tPA also prevents an approximately equal number of patients from experiencing symptomatic worsening from stroke extension, cerebral herniation, and other complications of large infarcts. Baldly stated, if you receive $\mathrm{PPA}$ the risk is increased that you may bleed and die. If you don't receive tPA the risk is increased that you may herniate and die. The salient number needed to harm is the net sum of these two factors, and across all under three hour trials there is no net harm. Analysing all seven trials with available under three hour data (NINDS 1 and 2, ECASS 1 and 2 , ATLANTIS A and B, Haley 1993), death occurred in $83 / 479(17.3 \%)$ of tPA treated patients and 83/478 (17.4\%) of placebo treated patients $(\mathrm{P}=0.9)$. Thus, the number needed to treat to produce benefit from tPA is as low as two, the number needed to treat to cause net harm approaches infinity. These numbers amply support the statement that tPA is highly efficacious.

Hoffman wishes the $B M J$ had solicited commentaries more accurately reflecting the balance of opinion on tPA in acute stroke. So do we. It is important, however, to realise what such balanced commentaries would look like. The typical opinion page dichotomy of one pro opinion and one con opinion that the $B M J$ arranged provides an entirely misleading view of the state of informed opinion. Among American experts on stroke there is overwhelming consensus that tPA is efficacious. A balanced set of expert commentaries would include an order of magnitude greater number of positive opinions than negative opinions.

Hoffman also erects a straw man. We never suggested that "it is impossible to be an expert on a subject about which one does not have a conflict of interest." Rather, we merely suggested that many experts will have minor competing interests. In this regard, it is noteworthy that in his letter Hoffman has declared his own financial competing interest with regard to the use of tPA in stroke. If he were to be true to the absolutist position on financial conflicts that he has advanced, he will now absent himself from advising influential and independent organisations on the IPA in stroke issue.

$\mathrm{Li}$ et al repeat the claim that the National Institute of Neurological Diseases and Stroke (NINDS) tPA study was a single trial. This myth was long ago demonstrated to be false but persists among tPA contrarians as an article of faith impervious to actual evidence. However devoutly the tPA contrarians wish they only had a single NINDS-tPA trial with which to contend, the fact is there were two trials, as the Food and Drug Administration recognised when ascertaining that the evidence for the benefit of tPA in acute stroke was quite adequate to approve the indication.

We will close by again seeking common ground. We concur, as before, with calls to bar experts with major financial competing interests from service on guideline committees and to require experts with minor financial competing interests to disclose them publicly. And we reiterate our concurrence with policy statements of the Brain Attack Coalition and the American College of Emergency Physicians that urge emergency physicians and other acute care providers to become expert in acute stroke care, including the use of tPA for acute stroke, and to place their hospitals on standby and divert patients to designated stroke centres where treatment can be expertly delivered. ${ }^{34}$

Jeffrey L Saver associate professor, neurology Chelsea S Kidwell assistant professor, neurology Sidney Starkman professor, emergency medicine and neurology

UCLA Stroke Center, Department of Neurology, and Department of Emergency Medicine, University of California, Los Angeles, USA

JLS, CSK, and SS have served as site investigators in acute stroke clinical trials sponsored by several ( 15 , 11 , and 17 respectively) pharmaceutical and biotechnology companies, including Genentech and Boehringer-Ingelheim; have received speaking honorariums from several $(12,5,8)$ pharmaceutical companies, including Genentech and BoehringerIngelheim; and have served as consultants on scientific advisory boards for several $(7,1,5)$ pharmaceutical and biotechnology companies developing acute stroke treaments, including Boehringer-Ingelheim and Genentech. JLS and SS have provided expert consultation in lawsuits against physicians involving the issue of use of $\mathrm{tPa}$ in acute stroke.

1 Haley EC Jr, Lewandowski C, Tilley BC. Myths regarding the NINDS rt-PA stroke trial: setting the record straigh Ann Emerg Med 1997;30:676-82.

2 FDA Center for Biologics Evaluation and Research. Clinical review for PLA 96-0350. 12 June 1996.

3 Alberts MJ, Hademenos G, Latchaw RE, Jagoda A, Marle JR, Mayberg MR, et al. Recommendations for the establishment of primary stroke centers. Brain Attack Coalition. JAMA 2000; 283:3102-9.

4 American College of Emergency Physicians Board of Directors. Policy statement: Use of intravenous tPA for the mactors. Policy statenent: Use of nhe ment Published acep.org/1,5006,0.html; accessed 16 May 2002

\section{Authors' reply to getting more for their dollar: Kaiser $v$ the NHS}

Editor-Our paper comparing the NHS with Kaiser Permanente has generated lively interest and, on the whole, a constructive debate. $^{12}$ Discerning commentators have noted that further refinement of the data and the analysis (which we strongly advocate) is unlikely to change the basic conclusions. These are that Kaiser Permanente offers improved performance at roughly the same cost and that, therefore, there are probably lessons to be learnt that would benefit the future performance of the 
NHS. We have further noted from the extensive debate that has followed the publication of our paper, that those without a political axe to grind and having a good working knowledge of both systems agree with this overall finding.

In light of this, we were amazed that the $B M J$ chose to publish such a distorted sample of the responses to our paper and did not even reference our extensive response to the comments raised by readers of bmj.com in our response of 7 February 2002. ${ }^{34}$ It is unfortunate that the $B M J$ chose to publish letters that were written by people who variously did not bother to read, did not understand, or seemed intent on misrepresenting the nature of our analysis and our conclusions. Space does not permit a comprehensive critique of all of the inaccuracies contained in the letters published on 1 June. We would note only that most of the letters contained serious factual errors and that the letter by Himmelstein and Woolhandler is particularly egregious in its misrepresentation.

Two persistent misunderstandings that occur in the letters published relate to the adjustment for purchasing power parity (PPP) and the nature of the comparison being made. The arguments for including the PPP adjustment have been clearly made and are robust. We are comparing two health delivery systems. We are not comparing two health finance systems and neither are we comparing the UK system as a whole with the US system as a whole. The cost environment in which the two delivery systems operate is exogenous to our analysis and therefore we control for it. We state clearly in our paper that we do not defend the inequitable financing system of the United States, neither do we hold it up as a model for the United Kingdom to emulate.

The good news is that, despite the extraordinary views published in the $B M J$, there are an increasing number of practitioners and policymakers in the United Kingdom who realise that increased investments alone will not provide the health service that the British public expect or deserve. Fundamental change in the way services are organised and managed will also be necessary. Luckily, some people are ready to listen and learn, which provides great hope for the future of the NHS.

Richard G A Feachem director

Institute for Global Health, University of California, San Francisco and Berkeley, CA 94105, USA

Neelam Sekhri chief executive officer

Healthcare Redesign Group, Alameda, CA 94502,

USA

Karen White programme development officer

Institute for Global Health, University of California

1 Feachem RGA, Sekhri NK, White KL. Getting more for their dollar: a comparison of the NHS with California's Kaiser Permanente with commentaries by J Dixon, DM Berwick, AC Enthoven]. BMJ 2002; 324: 135-43. (19 January.)

2 Electronic responses. Getting more for their dollar. bmj.com 2002. (bmj.com/cgi/eletters/324/7330/135; accessed 19 June 2002.)

3 Correspondence Getting more for their dollar: Kaiser the NHS. BMJ 2002;324:1332 (1 June.)

4 Sekhri NK, Feachem R, White K. The authors respond. Sekhri NK, Feachem R, White K. The authors respond. bmj.corar 2000 . (bmj.com/c

\section{Health care in Britain remains variable}

EDITOR-We have great empathy for the author of the personal view telling of the injustices surrounding her baby's birth and the cerebral palsy that followed. ${ }^{1}$ A traumatic labour is bad, and the added pain of a permanently damaged baby is a disaster. As recent parents who have had to endure two contrasting prolonged labours, but each with happy outcomes, we could not help but compare our experiences with that of the author.

We too had the added baggage of medical backgrounds. Our hopes of this being an advantage couldn't have been more misplaced during our first experience of labour in the NHS. Communication and compassion were in short supply. The hushed tones of staff discussing progress and the glossing over of details proved to be ominous. Middle grade medical opinion was sought only after 36 hours, when repeated examinations had been found to be incorrect and fetal distress was evident. Our second experience, though equally painful and lasting (only) half as long, couldn't have been more contrasting. Our medical status didn't seem to hinder the lines of communication, with regular updates from labour suite staff and persona review at least twice by the on call consultant.

The different experiences we have had reinforce the idea that health care in 21st century Britain remains hit and miss. Unless healthcare workers accept the raised expectations as a natural evolution of the genera raising of standards, and unless working conditions are changed such that senior skil is always available, the tragic scenario that the author bravely describes will continue to be repeated.

Lindsay Abraham staff nurse

23 Dene View, South Gosforth, Newcastle upon Tyne NE3 1PU

Alwyn Abraham specialist registrar in orthopaedics Department of Orthopaedics, University Hospital of North Durham, Durham DH1 5TW alwyn@lalabel.freeserve.co.uk

1 It can happen to anyone. BMJ 2002;324:985. (20 April.)

\section{PFI is here to stay}

\section{Select committee's report should have been given greater attention}

EdiTOR-Pollock's arguments against the private finance initiative (PFI), a news item on PFI, and a report on the House of Commons Select Committee on Health's inquiry into the role of the private sector in the NHS should have been linked together and more made of the select committee's report. ${ }^{1-3}$

The select committee said that it was "unimpressed with much of the University College London's Health Policy and Health Services Research Unit's (HPHSRU) research and its arguments against PFI." Yet the $B M J$ has based its debate on PFI almost exclusively around articles by this unit. The committee added: "This has raised serious questions about the HPHSRU's ability to analyse rationally the finances of the NHS.' Most significantly it said: "We found the lack of sound analysis from the HPHSRU additionally worrying because it has been the source of advice for many groups including unions and professional associations, all of whom have used parts of the unit's work as a justification for their antagonistic attitudes towards the private sector."

The select committee found that "PFI is still being blamed for numerous ills not directly related to it whereas the many benefits ascribed to PFI have yet to be proved. The time has come for a more rational and objective debate." It concludes: "Some of the antagonistic extreme views that are put forward by the HPHSRU and by other organisations have not helped to promote a sensible and mature debate about what is best for patients and staff in the NHS."

Surely the $B M J$ (and the BMA) should now move on from its blind antagonism to PFI. It should be more critical of the evidence it presents in its articles and engage rationally in the debate. Ultimately PFI is probably neither as bad nor as good as the extremists present. In the meantime we are being distracted from identifying and debating the real health questions that lie beyond arguments about how new hospitals are funded.

We need to consider what priorities drive us to spend so much of our NHS resources on hospital buildings and whether those priorities are right. Should an obsession with counting acute beds blind us to the health problems that cannot be solved by a hospital bed? How can health care (and even health) be delivered outside hospitals? We need to look at developing capacity to manage illness in a whole systems way as advocated by the national beds inquiry $y^{4}$ and how we incorporate acute hospital planning into a holistic approach to health planning and development as set out by the King's Fund. ${ }^{5}$ These are the real questions concerned with the best interests of patients.

Brian McCloskey professor of public health University College Worcester, Worcester WR2 6AJ B.McCloskey@worc.ac.uk

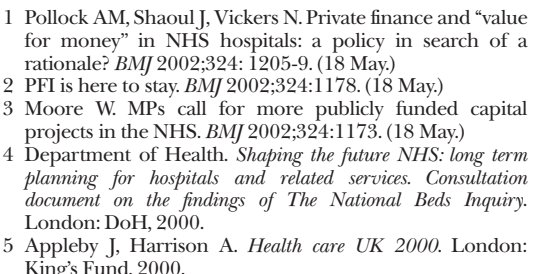
for money" in NHS hospitals: a policy in search of a rationale? BMJ 2002;324: 1205-9. (18 May.)

2 PFI is here to stay. BMJ 2002;324:1178. (18 May.)

3 Moore W. MPs call for more publicly funded capital projects in the NHS. BMJ 2002;324:1173. (18 May.)

4 Department of Health. Shaping the future NHS: long term planning for hospitals and related services. Consultation document on the findings of The National Beds Inquiry. London: $\mathrm{DoH}, 2000$.

5 Appleby J, Harrison A. Health care UK 2000. London: King's Fund, 2000.

\section{Select committee's report used parliamentary privilege unacceptably} EDITOR-We are deeply concerned at the misrepresentation in the House of Commons Select Committee on Health's report, The Role of the Private Sector in the NHS, of evidence critical of the private finance initiative (PFI) given by University College 
London's Health Policy and Health Services Research Unit. ${ }^{12}$

We believe that the committee's criticism of research by the unit is an unacceptable use of parliamentary privilege to attack academic scholarship. Paragraphs 65 to 69 of the report give an inaccurate account of statements made in evidence and in published research. In particular, they misrepresent evidence that the unit gave to the committee and allege that the unit's research was unsound without providing any evidence of this.

This will undoubtedly deter other researchers from acting as expert witnesses to select committees in the future, especially if their findings do not accord with prevailing government policies.

It is important that parliamentary select committees take evidence from witnesses with a wide range of views and examine them critically and robustly in relation to government policies. Contrary to the comments made in the report, the unit's published research on public health and the private finance initiative is respected both internationally and nationally.

We call on the House of Commons Health Committee to withdraw these unsubstantiated comments and urge others who support fair reporting and use of evidence given to select committees to reinforce this request. This can be done by writing to the House of Commons Health Committee, House of Commons, London SW1A 0AA or emailing the committee at healthcom@parliament.uk

Alison Macfarlane (City University), Bob Heyman (City University), Daniel Dorling (University of

Leeds), Dave Gordon (University of Bristol), George Davey-Smith (University of Bristol), Helen Dolk (University of Ulster), Helen Roberts (City University), Ian Basnett (consultant in public health), Ian Roberts (London School of Hygiene and Tropical Medicine), Jane Lewis (University of Oxford), Jennie Popay (University of Lancaster),

Martin McKee (London School of Hygiene and Tropical Medicine), Miranda Mugford (University of East Anglia), Rodney Barker (London School of Economics and Political Science), Rosalind Raine (London School of Hygiene and Tropical Medicine), Sally Baldwin (University of York), Sally Glen (City University), Stephen Platt (University of Edinburgh), Trevor Sheldon (University of York)

A.J.Macfarlane@city.ac.uk

1 House of Commons Select Committee on Health. The role of the private sector in the NHS. London: Stationery Office, of the private sector in

2 PFI is here to stay. BMJ 2002;324:1178. (18 May.)

\section{Ethics of limb allografts}

\section{Authors assume that they understand more than their patients do}

EDITOR-The term paternalism does not appear in the case descriptions by Benatar and Hudson, but it factors heavily in their discussion. ${ }^{1}$ The relative risks and merits of the proposed procedures are discussed from their viewpoint; the patient's (or parent's) insight is totally lacking. The fact that informed consent is not a perfect process is an unacceptable excuse for their decision to ignore the process. Such logic would suggest that we abandon informed consent altogether until it is perfected.

Every surgical procedure has associated risks and benefits; we should quantify them to the greatest degree possible and then work with our patients to match their beliefs and preferences with those risks and benefits.

The authors assume that they understand the risks and benefits of such a procedure with far more certainty than is justified. For example, they conclude that amputation among children poses less disadvantage than amputation later in life and that loss of the graft later in life would be more difficul than the original loss. Both of these conclusions are unsupported and, at best, debatable. Exactly how certain are the authors that a child with no hands or feet can expect normal longevity, and how dramatic is the reduction in quality of life associated with such a loss? A certain loss in quality of life must indeed be weighed against an uncertain risk of lost longevity, but such trade offs are best judged by informed patients and parents, hopefully with our guidance and support.

Finally, the authors suggest that the second patient's difficult social circumstances affect her suitability for transplantation. But a young girl with only an outside toilet would seem to have an extraordinary need for limb function-much greater than a child in advantaged circumstances with access to assistive devices.

Kenneth J Mukamal assistant professor of medicine Beth Israel Deaconess Medical Center, Boston, MA 02215, USA

kmukamal@caregroup.harvard.edu

\section{Benatar D, Hudson DA. A tale of two novel transplants not done: the ethics of limb allografts. BMJ 2002;324:971-3. (20 April.)}

\section{Authors' reply}

EDITOR-Mukamal offers three criticisms of our paper. In doing so, he misconstrues some of our arguments.

Firstly, he charges us with paternalism for not deferring to the patient's mother in the decision about transplantation. In doing so, he misunderstands our comments about informed consent. We were not suggesting that the imperfections of the informed consent process imply that it should be abandoned entirely. Instead, we drew a distinction "between the acceptability of a person choosing some risky or costly course, and someone else facilitating that person's assumption of the risk or cost." We were suggesting that there are some (but only some) surgical procedures in which the risks or costs are so great that it would be inappropriate for doctors to offer them. Nothing Mukamal says addresses that claim.

Secondly, Mukamal asserts that claims we make about the risks and benefits are unsupported. On the contrary, we did support them. Consider, for example, our claim, disputed by him, that amputation of a graft later in life would pose a greater disadvantage than being limbless from childhood. We noted that adaptation to life without limbs is easier at a younger age and that amputation of a graft later in life would lead to greater functional loss, given that "the limb would have to have been cut back for the original allograft." If Mukamal thinks that these considerations do not support our claim then he should say why.

Mukamal also asks how certain we are that a child with no hands or feet can expect normal longevity. Certainty is not the issue here. Nobody can be certain of how long anybody will live. The question, instead, is the likelihood of living a normal life span. We saw no reason for thinking that this patient's life would be shortened by her disability. Her life is more likely to be substantially shortened by transplantation than by having no hands and feet.

Finally, Mukamal criticises our suggestion that the deprived social circumstances are contributory but not decisive considerations against transplantation. He is right that poverty can exacerbate disability. Our point, however, is that the social circumstances tend to count against rather than in favour of transplantation. Mukamal ignores the fact that immunosuppressed people living in deprivation are more susceptible to opportunistic infections. And he ignores the considerable transport expenses for travelling to regular medical appointments. These problems are hardly offset by the additional burden of disability (over those who are more affluent) that the child experiences in consequence of her social circumstances

David Benatar associate professor Philosophy Department, University of Cape Town, Private Bag, Rondebosch 7700, South Africa dbenatar@humanities.uct.ac.za

Don A Hudson associate professor

Department of Plastic and Reconstructive Surgery, University of Cape Town, Observatory 7925 , South Africa

\section{Co-artemether has been used in ambulatory treatment of falciparum malaria}

EDITOR-D'Acremont et al report a study of the treatment of imported malaria in an ambulatory setting. ${ }^{1}$ We are the sole providers of care to a large group of non-immune expatriates and semi-immune Mozambicans in Maputo, diagnosing malaria by rapid antigen testing and microscopy. We report here on the treatment of non-immune patients with falciparum malaria.

Given the lack of adequate high level care facilities in Maputo, we have had to devise a treatment protocol for the ambulatory management of uncomplicated falciparum malaria. Patients with severe or complicated disease, as judged by World Health Organization criteria, are immediately started on intravenous quinine and evacuated to South Africa. Patients with uncomplicated disease, 
however, are given ambulatory treatment with a six dose course of co-artemether (artemether-lumefantrine). None has been admitted, all having been followed up as outpatients in our clinic.

To date, 75 patients have received ambulatory treatment with co-artemether. No other antimalarial treatment has been used. With this system of management we have achieved a $100 \%$ cure rate, as judged by parasite clearance and lack of further episodes of clinical malaria (as sole providers of care, we would have been made aware of any further episodes of malaria). No patient who received ambulatory treatment deteriorated or required rescue treatment; all made a full and uneventful recovery free of sequelae.

Our treatment protocol permitted ambulatory treatment of patients with parasitaemias of up to $5 \%$, provided no other sign of severe or complicated malaria was present. D'Acremont et al declined to give ambulatory treatment to patients with a $\%$ parasitaemia; our WHO criteria were otherwise similar to, but more comprehensive than, theirs.

We suspect that our results (currently being prepared for publication) are due to our use of a combination treatment that contains an artemisinin, the efficacy and rapidity of action of artemether preventing progression to severe or complicated malaria. The action of the artemisinins in the early stages of the erythrocytic phase of parasite development-an advantage not enjoyed by mefloquine-may also be a critical factor in the prevention of progression and help explain our results.

Stephen Toovey medical director

toovey@travelclinic.co.za

Andrew Jamieson medical director

Netcare Travel Clinics, South Africa, PO Box

786692, Sandton, 2146, South Africa

Competing interests: ST has been reimbursed by Novartis, manufacturers of co-artemether, for attending a conference and has received a fee for speaking. AJ has no competing interests.

1 D'Acremont V, Landry P, Darioli R, Stuerchler D, Pécoud A, Genton B. Treatment of imported malaria in an ambulatory setting: prospective study. BMJ 2002 324:875-7. [With commentary by C J M Whitty and D N J Lockwood.] (13 April.)

\section{Action is still needed to stem heterosexual transmission of HIV in Africa}

EDITOR-The startling statistic, reported by Eleni Papadopulos-Eleopulos et al, ${ }^{1}$ that it would take up to 222 years to achieve a $95 \%$ probability of becoming infected with HIV during heterosexual intercourse, will be small consolation to the people of southern Africa.

Heterosexual transmission of HIV-1 depends on the infectiousness of the index case and the susceptibility of the uninfected partner. Infectivity seems to vary during the course of illness and is not constant between individuals, ${ }^{2}$ each $\log _{10}$ increment of seminal
HIV RNA being associated with an $81 \%$ increased rate of HIV transmission. ${ }^{3}$

Rates of sexually transmitted disease, host genetic patterns, types of sexual practices, rates of male circumcision, nutritional status, antiretroviral treatment, and even prevalence of intestinal parasites are thought to influence HIV transmission. Infectivity depends critically on social, cultural, and political factors as well as the biological activity of the agent. Whether the epidemic grows or slows depends on infectivity plus two other variables: the duration of infectiousness and the average rate at which susceptible people change sexual partners. ${ }^{2}$

Public health programmes in Thailand have led to substantial changes in sexual behaviour among young men, especially an increased use of condoms; the rate of new HIV infections has also declined. ${ }^{4}$ According to UNAIDS, similar interventions are also working in Africa. In Uganda the prevalence of HIV among pregnant women in urban areas has fallen for eight years in a row, from a high of $29.5 \%$ in 1992 to $11.3 \%$ in 2000 . This reduction has been ascribed to efforts to promote sexual health. In Kampala almost $98 \%$ of sex workers surveyed in 2000 said they had used a condom the last time they had sex.

Coles et al have reported a cluster of cases of HIV infection in New York State in which one man infected 13 of 42 women after vaginal intercourse. ${ }^{5}$ In light of this Papadopulos-Eleopulos et al's assertion that "there is no more heterosexual transmission of HIV in Africa than anywhere else, including Britain, the United States, Australia, and Europe" may be valid. However, the message of their letter that the disease is not spread by sex in one country because of data obtained in another is fundamentally flawed. The argument about the exact incidence of HIV transmission per act of intercourse is academic; what is required is concerted action to educate and empower the people of sub-Saharan Africa to reduce the devastating impact of HIV/AIDS.

Douglas M G Bowley honorary lecturer dougbowley@mweb.co.za

Graeme J Pitcher consultant, division of paediatric surgery

Department of Surgery, University of the Witwatersrand, Johannesburg, South Africa

1 Papadopulos-Eleopulos E, Turner VF, Papadimitriou JM, Alfonso H, Page BA, Causer D, et al. Global voices on HIV/AIDS: Heterosexual transmission of HIV in Africa i no higher than anywhere else. BMJ 2002;324:1035. (27 April.)

2 Royce RA, Sena A, Cates W Jr, Cohen MS. Sexual transmission of HIV. N Engl J Med 1997;336:1072-8.

3 Tovanabutra S, Robison V, Wongtrakul J, Sennum S, Surivanon V, Kingkeow D, et al. Male viral load and Suriyanon V, Kingkeow D, et al. Male viral load and
heterosexual transmission of HIV-1 subtype E in northern heterosexual transmission of HIV-1 subtype E in nort 4 Nelson KE, Celentano DD, Eiumtrakol S, Hoover DR Beyrer C, Suprasert S, et al. Changes in sexual behavio and a decline in HIV infection among young men in Thailand. N Engl J Med 1996;335:297-303.

5 Coles FB, Birkhead GS, Johnson P, Smith PF, Berke R, Allenson P, et al. Cluster of HIV-positive young women-New York, 1997-1998. MMWR Morb Mortal Wkly Rep 1999;48:413-35.

\section{Clarifications: open access follow up for inflammatory bowel disease}

EDITOR-In our authors' reply to the letter by Barber and Thompson, we stated that further analysis of our data, using their recommended $t$ test on bootstrapped data, had confirmed the results of the non-parametric tests used in our original article. ${ }^{1-3}$ In other words, open access follow up for irritable bowel disease led to cost savings in secondary care. We have since discovered that a calculation error occurred in our bootstrapping exercise. The further analysis did not, in fact, confirm the statistical significance reported for secondary care, although it did confirm the original result that differences in overall costs (primary, secondary plus patient-borne costs) were not significant. We accept that bootstrapping is the preferred approach and that, on this basis, the study did not demonstrate resource savings in secondary care.

It is unfortunate that Bland's letter, published on bmj.com (bmj.com/cgi/eletters/ $320 / 7251 / 1730 \# 8480$ ) and in the journal, ${ }^{4}$ draws attention to a phrase in our authors' reply that was due to an unsanctioned editorial change and distorted our meaning. ${ }^{2}$ We did not claim that the savings in secondary care were great, and we drew attention to this promptly in our electronic reply to Bland. ${ }^{5}$ This reply was not published in the journal with Bland's letter.

J G Williams professor of health services research University of Wales Swansea, Swansea SA2 8PP j.g.williams@swan.ac.uk

D R Cohen professor of health economics Business School, University of Glamorgan, Pontypridd CF37 1DL

I T Russell professor of health sciences Department of Health Sciences and Clinical Evaluation, University of York, York YO10 5DD

1 Barber JA, Thompson SG. Open access follow up for inflammatory bowel disease. BMJ 2000;320:1730

2 Williams JG, Cohen DR. Open access follow up for inflammatory bowel disease. BMJ 2000;320:1730.

3 Williams JG, Cheung WY, Russell IT, Cohen DR, Longo M, Lervy B. Open access follow up for inflammatory bowel disease: pragmatic randomised trial and cost effectiveness study. BMJ 2000;320:544-8

4 Bland M. Confidence intervals should be used in reporting trials. BMJ 2000;321:1351.

5 Williams JG. Re: Confidence intervals should be used in reporting trials. bmj.com 2000. (bmj.com/cgi/eletters/ 320/7251/1730\#8620; accessed 19 June 2002.)

**We apologise for the unacceptable delay in publishing these clarifications.-Sharon Davies, letters editor

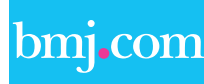

\section{Rapid responses}

Correspondence submitted electronically is available on our website 